\title{
AVALIAÇÃO DE VARIEDADES CRIOULAS DE MILHO PARA PRODUÇÃO ORGÂNICA NO SEMIÁRIDO POTIGUAR
}

\author{
B. B. ARAÚJO JUNIOR*, A. E. MELO, J. N. R. MATIAS E M. A. FONTES \\ ${ }^{1}$ Instituto Federal do Rio Grande do Norte (IFRN) \\ bernardo.bezerra@ifrn.edu.br*
}

Artigo submetido em agosto/2014 e aceito em junho/2015

DOI: 10.15628/holos.2015.2277

\section{RESUMO}

Com a expansão do comércio de cultivares híbridas, várias comunidades rurais têm abandonado suas sementes tradicionais, tornando o camponês mais dependente de multinacionais do setor de sementes. Porém, as sementes locais têm sua importância, seja do ponto de vista genético, ambiental, social e até mesmo econômico, e com base nisso, foi instalado um ensaio com cinco variedades crioulas e uma cultivar comercial de milho visando avaliar características de crescimento e produção, em sistema orgânico de produção na região semiárida do estado do Rio Grande do Norte. O ensaio foi conduzido na Horta Experimental do Instituto Federal do Rio Grande do Norte - Campus Ipanguaçu, com delineamento experimental em blocos ao acaso com três repetições e seis tratamentos. As variedades crioulas apresentaram o mesmo desempenho de crescimento e de produção observado na cultivar híbrida, com exceção para a característica massa de 100 grãos, em que a cultivar híbrida tendeu a apresentar os menores valores.

PALAVRAS-CHAVE: Zea mays, Agricultura orgânica, Soberania de sementes.

\section{EVALUATION OF MAIZE LANDRACES FOR ORGANIC PRODUCTION IN THE POTIGUAR SEMIARID}

\begin{abstract}
The expansion of trade in hybrid cultivars has promoted the abandonment of traditional seeds in many rural communities, causing the peasant become more dependent of multinational seed sector. However, landraces are important the genetic standpoint, environmental, social and even economic, and based on this, a study was carried with five local varieties and a commercial cultivar to evaluate growth and yield characteristics, grown under organic production system
\end{abstract}

in the semiarid region of Rio Grande do Norte state. The test was conducted at the experimental field of the Instituto Federal do Rio Grande do Norte - Campus Ipanguaçu with experimental design in randomized block with three replications and six treatments. The landraces showed the same growth performance and production observed in the hybrid cultivar, except for the characteristic 100 grains weight, wherein the hybrid cultivar tended to show lower values than the varieties.

KEYWORDS: Zea mays, Organic agriculture, Seed Sovereignty. 


\section{INTRODUÇÃO}

Com a crescente demanda por alimentos, pesquisas têm sido desenvolvidas com o intuito de gerar novas tecnologias e opções de manejo visando aumentar as produções. A manutenção e a possível expansão da cultura do milho como atividade comercial passam necessariamente pela eficiência com que os produtores conduzem as suas lavouras. A aplicação de determinada tecnologia influi diretamente nos custos de produção e determina também a produtividade da lavoura.

Grande parte da produção agrícola no Brasil se dá da forma tida como convencional a partir de uso de sementes híbridas comerciais e adubos sintéticos como fonte de nutrientes às plantas, o que torna o país um dos grandes consumidores de adubos minerais do mundo (MELAMED et al., 2007). A grande demanda energética para obtenção de fertilizantes sintéticos bem como os elevados custos de sementes acarretam no aumento do custo de produção, inviabilizando a mesma em pequenas propriedades agrícolas. Então, o resgate de variedades crioulas, bem como o uso de fontes de nutrientes naturais, pode reduzir o custo de produção, tornando o agricultor familiar mais sustentável a partir da adoção de um sistema de cultivo menos oneroso.

O reaproveitamento, safra após safra, de sementes colhidas em plantas selecionadas nas condições ambientais e nutricionais impostas pelo nível socioeconômico do agricultor proporciona o desenvolvimento de populações de milho adaptadas a diferentes situações. A variação genética entre as populações origina um conjunto genético adaptado que pode ser utilizado em programa de melhoramento regional para otimizar a interação de cultivares com o ambiente (MIRANDA et al., 2007).

As populações de variedades crioulas são importantes por constituírem fonte de variabilidade genética e o uso dessas variedades também apresenta diversas vantagens ligadas à sustentabilidade da produção como resistência a doenças, pragas e desequilíbrios climáticos, e podem ter as sementes armazenadas para as safras seguintes, o que diminui o custo de produção (PATERNIANI et al., 2000; CARPENTIERI-PÍPOLO et al., 2010). O ganho ambiental também é superior, uma vez que o uso de variedades crioulas, adaptadas localmente, mantém a diversidade genética das espécies, podendo servir de fonte para o melhoramento (CECCARELLI et al., 1994).

As variedades crioulas detêm combinações alélicas importantes e a substituição dessas por cultivares modernas não apenas vem gerando o processo de erosão genética, como também ameaça o conhecimento tradicional de cultivos peculiares (BOEF, 2007). Portanto, se os programas de melhoramento partirem de uma perspectiva participativa em que sejam direcionados para a exigência da agricultura local, será possível a obtenção de cultivares que realmente atendam as necessidades e exigências dos agricultores familiares nos aspectos econômicos, sociais e culturais. Para isso, torna-se necessário identificar as exigências dos agricultores e explorar a variabilidade entre variedades de milho crioulo.

Portanto, visando fazer o resgate de variedades locais de milho e assim fornecer ao agricultor opções mais acessíveis de material genético para cultivo, foi realizado um ensaio com o objetivo de avaliar a produção de grãos a partir de cinco variedades crioulas de milho em relação a uma cultivar híbrida, cultivados em sistema orgânico, para produção no Semiárido Potiguar. 


\section{MATERIAIS E MÉTODOS}

O ensaio foi conduzido na Horta experimental da Fazenda-Escola do Instituto Federal de Educação, Ciência e Tecnologia do Rio Grande do Norte (IFRN - Campus Ipanguaçu) localizado no distrito de Base Física, a $4 \mathrm{~km}$ do município de Ipanguaçu-RN (latitude $5^{\circ} 32^{\prime} 08^{\prime \prime} \mathrm{S}$, longitude $36^{\circ}$ $52^{\prime} 13^{\prime \prime} \mathrm{O}$ e altitude de $22 \mathrm{~m}$ ), entre os meses de dezembro de 2013 e abril de 2014. O clima da região, de acordo com a classificação de Köppen, é do tipo BSwh', ou seja, quente e seco, com precipitação pluviométrica bastante irregular, com média anual de $903,3 \mathrm{~mm}$, temperatura média anual de $27,9^{\circ} \mathrm{C}$ e umidade relativa do ar média de $70 \%$ (COSTA; SILVA, 2008).

O experimento foi conduzido em campo sob condições de cultivo orgânico acessível à agricultura familiar da região do Vale do Açu. O solo da área é classificado como NEOSSOLO FLÚVICO (EMBRAPA, 2006), e a sua fertilidade está descrita na Tabela 1.

Tabela 1. Análise química do solo da área experimental, da camada de 0 - $10 \mathrm{~cm}$. Ipanguaçu - RN, 2014.

\begin{tabular}{|c|c|c|c|c|c|c|c|c|}
\hline $\mathrm{pH}$ & $P$ & $\mathrm{~K}^{+}$ & $\mathrm{Na}^{+}$ & $\mathrm{Ca}^{2+}$ & $\mathrm{Mg}^{2+}$ & SB & $\mathrm{T}$ & $\mathrm{MO}$ \\
\hline $\mathrm{H}_{2} \mathrm{O}$ & --- & -------- & $---m g ~ c$ & -------- & - & \multicolumn{2}{|c|}{$--\mathrm{cmol}_{\mathrm{c}} \mathrm{dm}^{-3}$--- } & $\%$ \\
\hline 6,66 & 53,80 & 14,59 & 40,03 & 13,79 & 6,64 & 0,33 & 0,33 & 1,23 \\
\hline
\end{tabular}

A área foi previamente preparada com duas gradagens, e foi feita adubação de plantio utilizando esterco bovino/ovino (1/1) curtido, fertilizante composto classe A BIO-ORGAN (Tabela 2) e pó de rocha MB-4, nas doses de 7,0; 2,0 e 1,0 $\mathrm{Mg} \mathrm{ha}^{-1}$, respectivamente, totalizando $10 \mathrm{Mg} \mathrm{ha}$ ${ }^{1}$ da mistura. Os adubos foram distribuídos e incorporados na linha de plantio. O MB-4 apresenta uma composição rica em muitos elementos, que além da eficácia como fertilizante, promove maior resistência vegetal ao ataque de enfermidades (PINHEIRO; BARRETO, 1996).

Tabela 2. Composição do fertilizante composto classe A BIO-ORGAN utilizado no ensaio. Ipanguaçu - RN. 2014.

\begin{tabular}{cccccccccc}
\hline $\mathrm{pH}$ & $\mathrm{N}$ & $\mathrm{P}$ & $\mathrm{K}^{+}$ & $\mathrm{Ca}^{2+}$ & $\mathrm{Mg}^{2+}$ & $\mathrm{S}$ & $\mathrm{MO}$ & $\mathrm{C} / \mathrm{N}$ & $\mathrm{CTC}$ \\
\hline 6,5 & 1,0 & 10 & 1,5 & 12,0 & 1,0 & 1,0 & 25,0 & $18 / 1$ & $\mathrm{mmol}_{\mathrm{c}} \mathrm{kg}^{-1}$ \\
\hline
\end{tabular}

O delineamento experimental foi em blocos casualizados com três repetições e seis tratamentos que consistiram de cinco variedades crioulas de milho e uma cultivar híbrida comercial. A semeadura foi realizada com espaçamento de 1,0 m entre fileiras e $0,40 \mathrm{~m}$ entre plantas, com duas plantas por cova, resultando em uma densidade de 50.000 plantas por hectare.

Cada parcela experimental foi composta por quatro fileiras de plantas com 4,0 m de comprimento, sendo as fileiras laterais e as covas das extremidades das fileiras centrais consideradas como bordadura. Foi realizado o manejo da lagarta-do-cartucho (Spodoptera frugiperda), feito através de quatro pulverizações com periodicidade semanal, a partir dos 15 dias após a emergência, utilizando extrato de neem (Azadirachta indica).

As variedades crioulas utilizadas foram obtidas em comunidades rurais no estado do Rio Grande do Norte, sendo elas as seguintes: Morgana, oriunda da cidade de Angicos-RN; Zé moreno; D’angola; Tardão e Vida longa, da cidade de Apodi-RN. Para comparação e avaliação de desempenho destas variedades, foi utilizado também um híbrido comercial amplamente utilizado na região. Durante o ensaio, foi controlada a polinização, visando prevenir perda ou misturas de materiais. 
As características avaliadas foram relativas ao crescimento e a produção de grãos de milho. Para o crescimento foi avaliada a altura da planta e de inserção da primeira espiga aos 70 dias após a emergência. Para a altura da planta, foi considerada a distância do nível do solo ao ponto de inserção da lâmina foliar mais alta. A altura de inserção da espiga foi medida do nível do solo até a base da espiga mais elevada, no caso de plantas prolíficas.

A colheita do milho seco para avaliação de grãos ocorreu quando estes apresentaram teor de umidade em torno de $20 \%$, o que se deu, aproximadamente, aos 110 dias após a emergência, sendo a irrigação suplementar suspensa 15 dias antes. As variáveis analisadas para milho grão foram: número de grãos por espiga, massa de 100 grãos e rendimento de grãos. A massa e rendimento de grãos foram corrigidos para um teor de umidade igual a 15,5\% (base úmida).

Foi realizada a análise estatística a partir da análise de variância e posterior teste de média, quando conveniente, utilizando o software SISVAR 5.3 (FERREIRA, 2011).

\section{RESULTADOS E DISCUSSÃO}

O padrão de espigas colhidas variou em função da variedade, sendo que a cultivar comercial tendeu a produzir espigas menores, quando comparada às demais variedades, como pode ser observado na Figura 1. Na Tabela 3 é observado o resumo da análise de variância para as características de crescimento e de produção para as variedades crioulas e híbrido comercial avaliados.

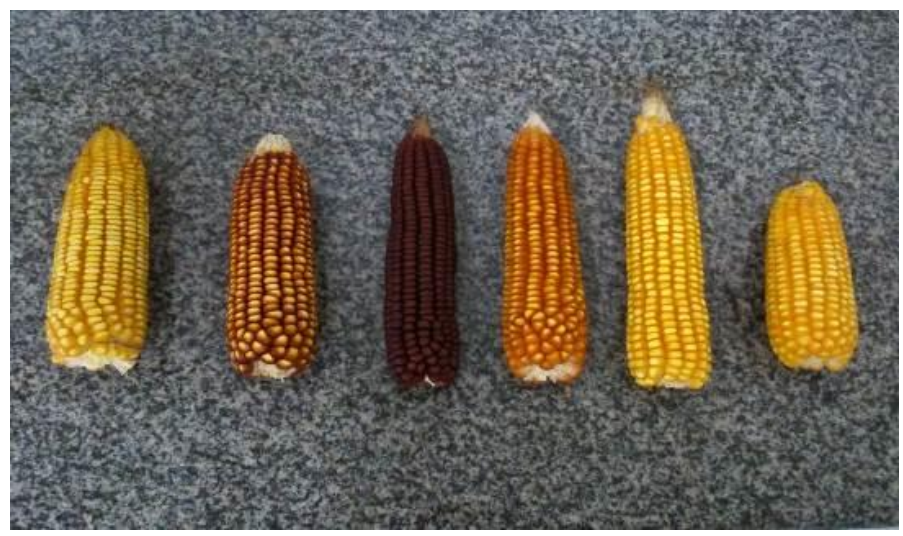

Figura 1. Espigas das variedades crioulas Morgana, Zé moreno, D’angola, Tardão, Vida longa e híbrido comercial, respectivamente, em sistema de cultivo orgânico, observadas imediatamente após colheita. Ipanguaçu - RN.

2014.

Tabela 3. Resumo da análise de variância contendo graus de liberdade, quadrado médio para tratamento, coeficiente de variação e significância do teste F para as características de crescimento e de produção avaliadas. Ipanguaçu - RN. 2014.

\begin{tabular}{lcrc}
\hline \multicolumn{1}{c}{ Característica avaliada } & Grau de liberdade & Quadrado médio & Coeficiente de variação \\
\hline Altura de plantas & 5 & $357,4951^{\text {ns }}$ & 10,69 \\
Altura de espiga & 5 & $376,3722^{\text {ns }}$ & 13,47 \\
Massa de 100 grãos & 5 & $31,4086^{*}$ & 8,71 \\
Grãos por espiga & 5 & $4244,9449^{\text {ns }}$ & 12,54 \\
Rendimento & 5 & $517393,4755^{\text {ns }}$ & 24,49 \\
\hline
\end{tabular}

${ }^{*} ;{ }^{\text {ns: }}$ significativo a $5 \%$ de probabilidade e não significativo, respectivamente, pelo teste $\mathrm{F}$ da análise de variância.

Com base na Tabela 3, observa-se que para as características de crescimento altura de plantas e altura de inserção da primeira espiga, não foram observadas diferenças significativas. 
Isto indica que, nas condições em que o ensaio foi conduzido, as variedades crioulas apresentaram desenvolvimento semelhante ao observado na cultivar híbrida comercial. Entre as características de produção, para número de grãos por espiga e para rendimento não foram observadas diferenças significativas, sendo estas observadas somente para massa de 100 grãos. Os valores médios observados no ensaio para as características avaliadas estão dispostos na Tabela 4.

Tabela 4. Médias observadas para as características de crescimento e de produção avaliadas nas variedades de milho testadas. Ipanguaçu-RN. 2014.

\begin{tabular}{lccccc}
\hline $\begin{array}{c}\text { Variedades de } \\
\text { milho* }\end{array}$ & $\begin{array}{c}\text { Altura da planta } \\
- \text {-cm-- }\end{array}$ & $\begin{array}{c}\text { Altura de inserção } \\
\text { da espiga } \\
-- \text { cm-- }\end{array}$ & $\begin{array}{c}\text { Massa de } \\
100 \text { grãos } \\
-- \text { g -- }\end{array}$ & $\begin{array}{c}\text { Número de grãos } \\
\text { por espiga }\end{array}$ & $\begin{array}{c}\text { Rendimento } \\
\text { Kg ha }\end{array}$ \\
\hline Morgana & $170,60 \mathrm{a}$ & $86,93 \mathrm{a}$ & $31,60 \mathrm{ab}$ & $386 \mathrm{a}$ & $1786,4 \mathrm{a}$ \\
Zé moreno & $148,93 \mathrm{a}$ & $74,39 \mathrm{a}$ & $35,89 \mathrm{a}$ & $377 \mathrm{a}$ & $1404,3 \mathrm{a}$ \\
D’angola & $180,30 \mathrm{a}$ & $101,06 \mathrm{a}$ & $31,02 \mathrm{ab}$ & $346 \mathrm{a}$ & $2271,3 \mathrm{a}$ \\
Tardão & $163,78 \mathrm{a}$ & $82,98 \mathrm{a}$ & $34,80 \mathrm{ab}$ & $398 \mathrm{a}$ & $2360,9 \mathrm{a}$ \\
Vida longa & $173,42 \mathrm{a}$ & $92,03 \mathrm{a}$ & $35,61 \mathrm{a}$ & $445 \mathrm{a}$ & $1857,1 \mathrm{a}$ \\
Híbrido comercial & $161,55 \mathrm{a}$ & $70,85 \mathrm{a}$ & $27,68 \mathrm{~b}$ & $342 \mathrm{a}$ & $2494,6 \mathrm{a}$ \\
\hline Média & 166,43 & 84,71 & 32,77 & 382 & 2028,8 \\
\hline \multicolumn{4}{r}{ *: Médias seguidas pela mesma letra, na coluna, não diferem entre si pelo teste SNK a 5\% de probabilidade }
\end{tabular}

Para massa de 100 grãos, os maiores valores foram observados nas variedades crioulas Vida Longa e Zé Moreno, com 35,61 e 35,89 g, respectivamente, diferindo significativamente da cultivar melhorada que apresentou a menor média, com 27,68 g, não apresentando diferenças significativas entre as demais variedades crioulas. Portanto, a cultivar híbrida tendeu a produzir grãos menores, em relação às variedades crioulas.

Para número de grãos por espiga, os maiores valores foram observados na variedade Vida longa com 445 grãos por espiga, e os menores valores observados no híbrido com 342 grãos por espiga, porém para esta característica não foram observadas diferenças significativas entre os materiais estudados. Semelhantemente ao que foi observado em número de grãos por espiga, para rendimentos não foram observadas diferenças significativas entre os materiais genéticos estudados (Tabela 4).

Os valores médios observados para rendimento de grãos nos genótipos testados variaram de 1404,3 a 2494,6 kg ha-1, sendo estes obtidos na variedade "Zé moreno" e no híbrido comercial, respectivamente. Esses valores para rendimento de grãos foram baixos quando levados em consideração a média nacional, que em 2010 foi de 4349,0 kg ha-1. Porém, essas produtividades foram superiores ao rendimento médio de grãos de milho apresentado pelo estado do Rio Grande do Norte, que no ano de 2010 foi de $424 \mathrm{~kg} \mathrm{ha}^{-1}$ (IBGE, 2010).

Pesquisas têm demonstrado que, de maneira geral, as populações crioulas são menos produtivas que as cultivares comerciais (PATERNIANI et al., 2000). Brito et al. (2005), trabalhando com diferentes materiais genéticos em diversos ambientes no estado do Pernambuco, observaram que os híbridos superaram em até $30 \%$ o rendimento médio das variedades crioulas.

Por outro lado, Araújo et al. (2013) testando variedades crioulas e cultivares híbridas comerciais em diferentes níveis tecnológicos de cultivo no norte do estado de Minas Gerais, puderam inferir que as variedades crioulas foram capazes de responder positivamente à aplicação de tecnologia no manejo da cultura tanto quanto os híbridos. Machado et al. (2003) também observaram que as variedades crioulas de milho, quando cultivadas em solo com baixo teor de $\mathrm{N}$, tendem a se sobressair em relação as cultivares híbridas comerciais, isso ocorre em virtude de as 
variedades crioulas de milho serem genótipos de base genética ampla, capazes de responder melhor aos estresses abióticos e bióticos (EICHOLZ et al., 2013). Em outros estudos com diferentes genótipos de milho, também foi observado desempenho semelhante ou até mesmo superior das variedades crioulas em relação as cultivares comerciais (MENEGUETTI et al., 2002).

\section{CONCLUSÃO}

Neste sistema orgânico de produção as variedades crioulas apresentaram resultados semelhantes aos valores observados na cultivar híbrida para as características de crescimento e de produção de grãos, com exceção para massa de 100 grãos, característica essa em que o híbrido apresentou os menores valores.

\section{REFERÊNCIAS}

1. ARAÚJO, A. V.; BRANDÃO JUNIOR, D. S.; FERREIRA, I. C. P. V.; COSTA, C. A.; PORTO, B. B. A. Desempenho agronômico de variedades crioulas e híbridos de milho cultivados em diferentes sistemas de manejo. Revista Ciência Agronômica, v. 44, n. 4, p. 885 - 892, 2013.

2. BOEF, W. S. Biodiversidade e agrobiodiversidade. In: BOEF, W. S.; THIJSSEN, M. H.; OGLIARI, J. B.; STHAPIT, B. R. (Org.) Biodiversidade e agricultores: fortalecendo o manejo comunitário. Porto Alegre: L\&PM, 2007. cap. 2, p. 36-40.

3. BRITO, A. R. M. B.; TABOSA, J. N.; CARVALHO, H. W. L.; SANTOS, M. X.; TAVARES, J. A.; DIAS, F. M.; NASCIMENTO, M. M. A.; TAVARES FILHO, J. J.; SOUZA, E. M. Adaptabilidade e estabilidade de cultivares de milho no Estado de Pernambuco. Revista Ciência Agronômica, v. 36, n. 3, p. 348-353, 2005

4. CARPENTIERE-PÍPOLO, V.; SOUZA, A.; SILVA, D. A.; BARRETO, T. P.; GARBUGLIO, D. D.; FERREIRA, J. M. Avaliação de cultivares de milho crioulo em sistema de baixo nível tecnológico. Acta Scientiarum. Agronomy, v. 32, n. 2, p. 229-233, 2010.

5. CECCARELLI, S. Specific adaptation and breeding for marginal conditions. Euphytica, v. 77, n. 3, p. 205-219, 1994.

6. COSTA, J. R. S.; SILVA, F. M. Análise da precipitação na cidade de Ipanguaçu/RN por imagens de satélite e distribuição de gumbel. In: SIMPÓSIO BRASILEIRO DE GEOGRAFIA FÍSICA APLICADA, 13. Viçosa-MG. Anais... Viçosa-MG. 2008.

7. EICHOLZ, E. D.; EICHOLZ, M.; FONSECA, E.; SILVA, S. D. A. Avaliação agronômica de variedades de milho no sul do RS. REUNIÃO TÉCNICA ANUAL DO MILHO, 58. Pelotas-RS. Anais...PelotasRS, 2013.

8. EMBRAPA. Sistema brasileiro de classificação de solos. Brasília: EMBRAPA-SPI. 2006. 412p.

9. FERREIRA, D. F. Sisvar: a computer statistical analysis system. Ciência e Agrotecnologia, v. 35, n.6, p. 1039-1042, 2011

10. IBGE. Levantamento sistemático da produção agrícola. v. 23, n. 12, p. 1-80, Rio de Janeiro, 2010.

11. MACHADO, A. T.; MACHADO, C. T. T.; MIRANDA, G. V.; COELHO, C. H. M.; GUIMARÃES, L. J. M. Resposta de variedades de milho a níveis e fontes de nitrogênio. Planaltina: Embrapa 
Cerrados, 2003. 27 p. (Boletim de Pesquisa e Desenvolvimento, 93).

12. MELAMED, R.; GASPAR, J.C.; MIERKELEY, N. Pó-de-rocha como fertilizante alternativo para sistemas de produção sustentáveis em solos tropicais. Rio de Janeiro: Centro de Tecnologia Mineral, 2007. Série de Estudos e documentos, 72, 24p.

13. MeneguetTI, G. A.; GIRARDI, J. L.; REgINATTO, J. C. Milho crioulo: tecnologia viável e sustentável. Agroecologia e Desenvolvimento Rural Sustentável, v. 3, n. 1, 2002.

14. MIRANDA, G. V.; SOUZA, L. V.; SANTOS, I. C.; MENDES, F. F. Resgate de variedades crioulas de milho na região de Viçosa-MG. Revista Brasileira de Agroecologia, v. 2, n. 1, p. 1145-1148, 2007.

15. PATERNIANI, E.; NASS, L. L.; SANTOS, M. X. O valor dos recursos genéticos de milho para o Brasil: uma abordagem histórica da utilização do germoplasma. In: UDRY, C.W.; DUARTE, W. (Org.) Uma história brasileira do milho: o valor dos recursos genéticos. Brasilia: Paralelo 15, 2000. p.11-41.

16. PINHEIRO, S.; BARRETO, S. B. MB4: Agricultura sustentável, trofobiose e biofertilizantes. Canoas-RS: La Salle. 1996. 273p. 